\title{
Electrical carotid baroreceptor stimulation
}

\author{
Jürg Schmidli · Regula S. von Allmen · Markus G. Mohaupt
}

Received: 8 September 2014 / Accepted: 28 October 2014 / Published online: 20 November 2014 (C) Springer-Verlag Wien 2014

Summary The Barostim neo ${ }^{\mathrm{TM}}$ system is a novel implantable device that activates the carotid baroreflex. It decreases the sympathetic activity and inhibits the renin system, which results in reduced blood pressure and heart rate. In patients with resistant hypertension, electrically activation of the baroreflex leads to an average decrease in systolic blood pressure of 38, 36, 40 and $53 \mathrm{mmHg}$ at 1, 2, 3 and 4 years, respectively. Additionally, cardiac remodelling with reduced left ventricular mass and posterior wall thickness has been observed in longterm studies. In a limited number of patients with heart failure, baroreflex activation therapy leads to a decrease in muscle sympathetic nerve activity and to improved quality of life and functional capacities. The implantation procedure is safe and associated with risks comparable with those of other active implantable devices. Barostim $\mathrm{neo}^{\mathrm{TM}}$ is currently available in several European countries.

Keywords Baroreflex activation therapy · Drug-resistant hypertension $\cdot$ Heart failure $\cdot$ Barostim neo ${ }^{\mathrm{TM}}$

\section{Interventionelle kardiovaskuläre Therapie bei Bluthochdruck}

Zusammenfassung Das Barostim neo ${ }^{\mathrm{TM}}$ System ist ein neues Gerät, welches elektrisch den Baroreflex-Mechanismus aktiviert (Karotisstimulator). Durch die

Prof. Dr. med. J. Schmidli $(\varangle) \cdot$ Dr. med. R. S. von Allmen, MD Dept of Cardiovascular Surgery, Bern University Hospital, 3010 Bern, Switzerland

e-mail: juerg.schmidli@insel.ch

Prof. Dr. M. G. Mohaupt

Dept of Nephrology, Hypertension and Clinical Pharmacology, Bern University Hospital,

Bern, Switzerland
Reduktion des Sympathikotonus und das Dämpfen das Renin-Systems bewirkt es ein Absenken von Blutdruck und Herzfrequenz. Bei Patienten mit therapierefraktärer Hypertonie führte die elektrische Aktivierung des Baroreflexes im Langzeit-Verlauf zu einer dauerhaften durchschnittlichen Senkung des systolischen Blutdrucks um 38, 36, 40 und 53 mmHg nach 1, 2, 3 und 4 Jahren. Ausserdem konnte bei diesen Patienten eine Reduktion der links-ventrikulären Masse und der posterioren Wanddicke beobachtet werden. Bei einigen Patienten mit Herzinsuffizienz konnte eine Reduktion der sympathischen Muskelaktivität bewirkt werden und eine wesentliche Verbesserung der Lebensqualität und der körperlichen Leistung beobachtet werden. Die Implantation des Gerätes gilt als sicher; die Risiken sind vergleichbar mit anderen implantierbaren Stimulatoren. Barostim neo ${ }^{\mathrm{Tm}}$ ist nun in mehreren europäischen Ländern erhältlich.

Schlüsselwörter Elektrische Baroreflex Aktivierung · Therapierefraktäre Hypertonie · Herzinsuffizienz · Barostim neo $^{\text {ts }}$

\section{Introduction}

Arterial hypertension, defined as systolic blood pressure (SBP) above $140 \mathrm{mmHg}$ or diastolic blood pressure above $90 \mathrm{mmHg}$, affects more than $30 \%$ of adults in the western world. Patients with a blood pressure of 140/90 $\mathrm{mmHg}$ have a risk for cardiac events twice as high as those with blood pressures of less than $130 / 80 \mathrm{mmHg}$, and the risk of cardiovascular death doubles with each increment of 20/10 mmHg above 115/75 mmHg [1]. Similarly, effective antihypertensive treatment is able to reduce the risk for stroke, myocardial infarction and congestive heart failure by up to $50 \%[2,3]$. However, hypertension can be effectively treated by best medical treatment (i.e. lowered to pressures of $140 / 90 \mathrm{mmHg}$ or below) only in $25-34 \%$ of 
patients, as many patients are resistant to medical treatment or demonstrated limited adherence to lifelong therapy [1]. And many of these resistant patients suffer from hypertension severe enough to place them at imminent risk of virulent cardiovascular disease.

So far, blood pressure management is dominated by antihypertensive medication. But, other non-drugrelated therapeutic options have been advocated in the past decade: electrical baroreceptor stimulation, biofeedback and other psychosomatic approaches, renal artery denervation as well as vaccination against high blood pressure. Unfortunately, the last two treatment modalities (renal artery denervation and vaccination) have recently been shown to be unsuccessful $[4,5]$. In contrast, electrical stimulation of the carotid sinus baroreflex is known to decrease blood pressure via intrinsic neurohumoral pathways [6] and represents a valuable therapeutic adjunct in patients with resistant hypertension.

The aim of this paper is to review the pathophysiological mechanisms of carotid baroreflex, to describe the second generation neurostimulating devices and associated surgical techniques and to summarise the current results in the treatment of resistant arterial hypertension.

\section{History}

The importance of the baroreflex for blood pressure regulation has already been recognised many decades ago [7]. In humans, baroreceptors are situated mainly in the aortic arch, the subclavian arteries and the carotid sinuses of which the dominant one is the carotid baroreflex. The anatomical distribution and feedback mechanisms of the baroreceptor nerve fibres have been investigated extensively [8] (Figs. 1 and 2). In brief, raising blood pressure increases stretch of the carotid sinus wall and subsequently activates the distortion receptors known as baroreceptors in the carotid sinus wall, which results in an increased frequency and amplitude of afferent nerve impulses. These impulses are then integrated in the medulla where neurohumoral and autonomic nervous system activities are modulated leading to an adjusted function of the heart, the kidneys and the peripheral vasculature resistance, which in turn leads to appropriate arterial pressure levels again.

Accordingly, electrical stimulation of the carotid sinus nerve reduces blood pressure and heart rate. As early as the 1960s and 1970s, carotid baroreflex stimulation was used to support the treatment of resistant hypertension in selected patients [6]. The approach, however, was aborted not only due to the limitations of the implantable devices and the development of more potent medication but also due to industry's preferred interest in the pacemaker development at the time. Some treated patients, however, were investigated decades later [9]. These observations demonstrated together with more recent data from animal studies that carotid baroreflex

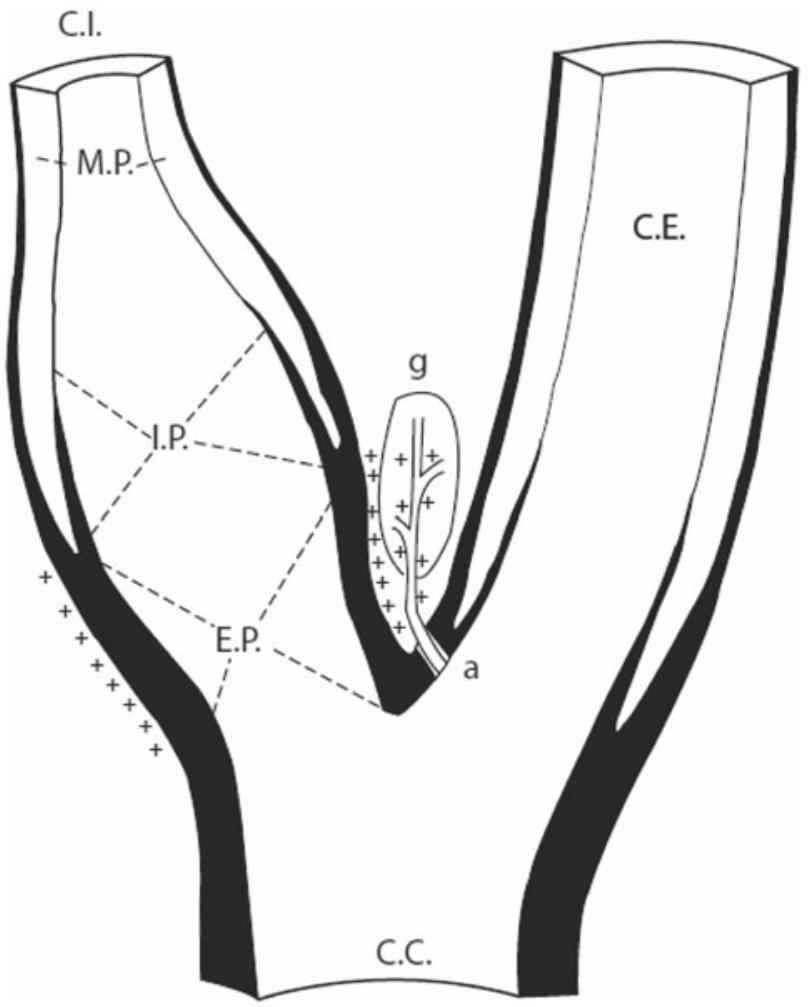

Fig. 1 Carotid bifurcation in man. In the carotid sinus one may distinguish a proximal elastic portion (E.P.) abundantly supplied with baroreceptors (+), an intermediate portion (I.P.) and a distal muscular portion (M.P.). The artery (a) of the carotid body $(g)$ has elastic structure and arises from the root of the external carotid. Common carotid (C.C.), internal carotid (C.I.), external carotid (C.E.). [8]

stimulation is indeed able to influence the long-term regulation of arterial blood pressure [10, 11].

\section{Device and surgical technique}

The first-generation device was the Rheos System Baroreflex Activation Therapy Device (CVRx Inc., Minneapolis, MN, USA) consisting of bilateral carotid sinus leads and a battery powered, programmable internal pulse generator (IPG). Thereby, the leads conduct the activation energy from the pulse generator to the baroreceptor fibres in the vessel walls of both carotid sinuses. The device is telemetrically programmable by an external system, which allows non-invasive adjustments of the stimulation parameters. The new generation device includes an IPG and only one lead. Therefore, baroreceptor stimulation is now performed only unilaterally. Moreover, the electrode and the IPG have become much smaller (Figs. 3 and 4) and further refinements in hardware and software have lead to battery longevity of 48 months on average, depending on the unique programming for each patient. The new design employs monopolar stimulation with the IPG serving as an active electrode. The design allows for greater penetration of the electrical current 
Fig. 2 Baroreflex pathway and feedback mechanism

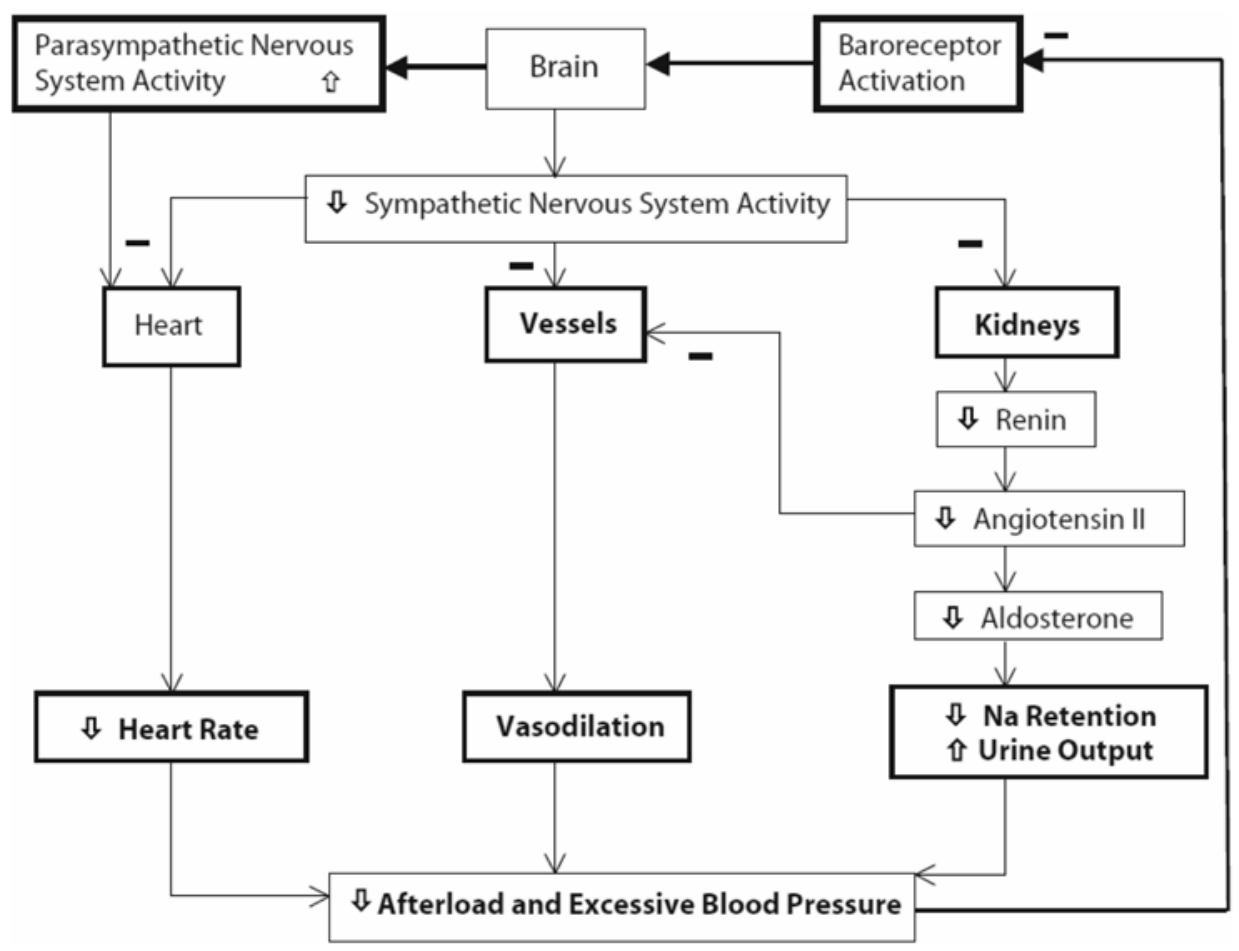

Fig. 3 First $\left(\right.$ Rheos $\left.^{\circledR}\right)$ and second (Barostim neo ${ }^{\text {TM }}$ ) generation baroreflex activation systems

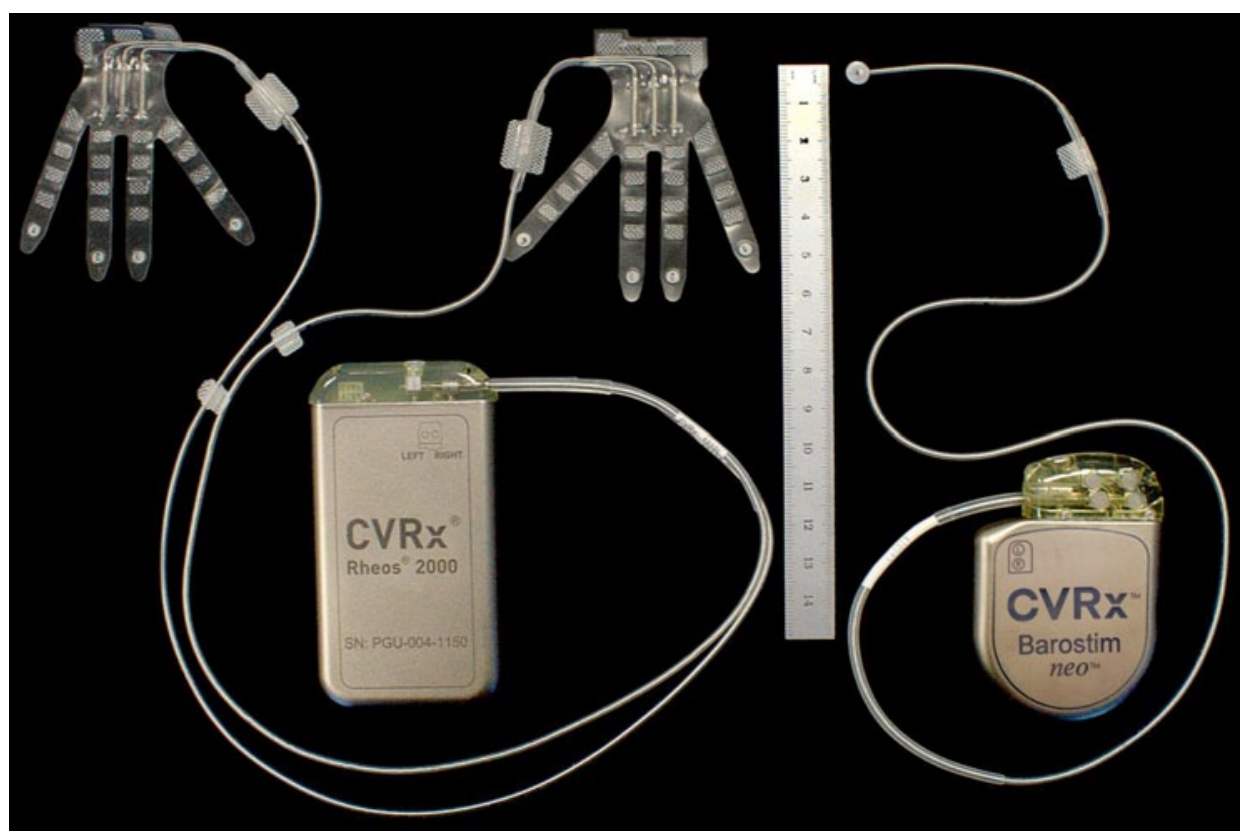

into the media of carotid artery where the baroreceptors are located, and the output of the IPG is now delivered a constant current.

During surgical device implantation, the patient is positioned in a supine position so that the two incisions can be accessed easily, one over the right carotid bifurcation and the other just beneath the right collarbone (Fig. 5). The carotid artery bifurcation is exposed and the anterior wall of the carotid sinus mobilised, while the vagal nerve as well as the superior root of the ansa cervicalis nervi hypoglossi are protected. Crucially, dissection within the bifurcation must be avoided to prevent injury to the neurovascular bundle and, thus, to the baroreflex [12]. So far, all procedures have been performed under general anaesthesia and any antihypertensive medication is maintained during the perioperative phase, except for beta-adrenergic blockers.

For the carotid sinus lead application and their intraoperative testing, any inhalational anaesthetics should be reduced and (partly) replaced by barbiturates or benzodiazepines to avoid pharmacological inhibition of the baroreflex [12]. Then, the electrode is positioned in various locations on the carotid bifurcation and electrical stimulation is started to localise the optimum haemody- 
Fig. 4 Surface of electrode tip touching the carotid wall (unipolar design, 2-mm diameter coated cathode) and implantable pulse generator of the second generation Barostim neo ${ }^{\mathrm{TM}}$
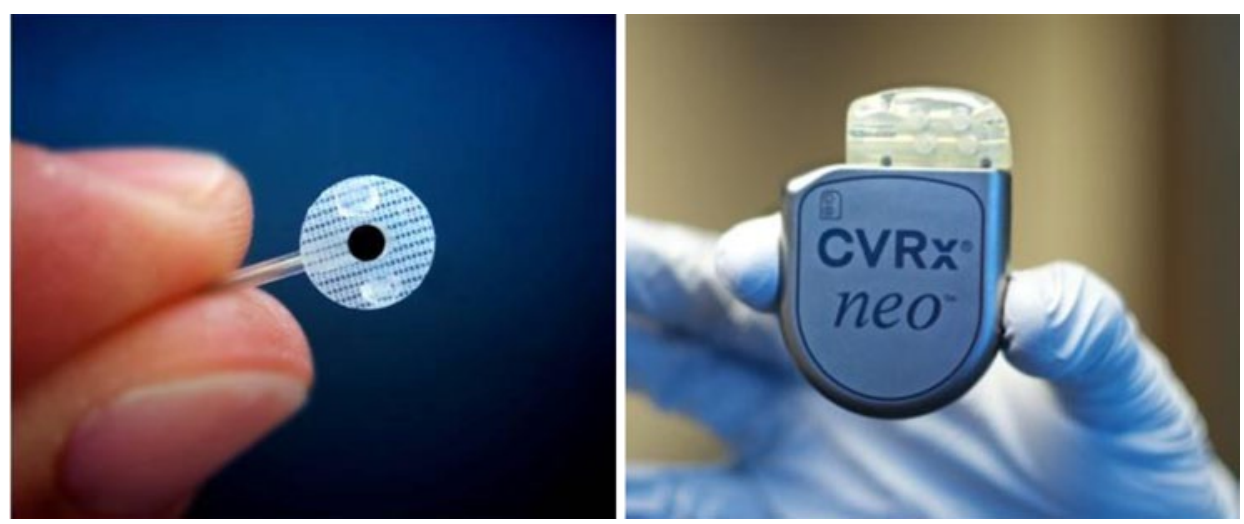

Fig. 5 Illustration of the Barostim neo ${ }^{\mathrm{TM}}$ system consisting of a unilateral electrode and lead and an implantable pulse generator. Programming is performed via radiofrequency telemetry by an external laptop-based programmer

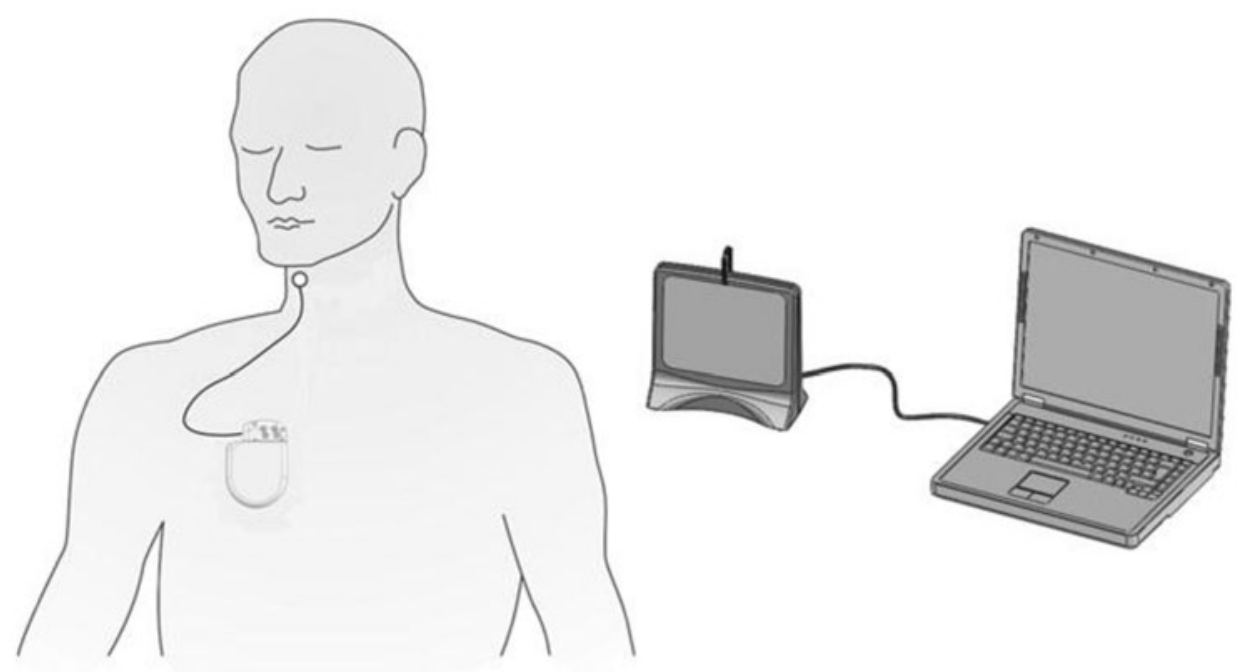

namic response ('mapping'). Once the optimal location is confirmed, the electrode is sutured in place. A strain relief loop is formed and fixed to the common carotid artery. Afterwards, the lead is tunnelled subcutaneously first towards the jugulum and second in a 90-degree angle towards the incision for the pulse generator. Subsequently, the pulse generator is implanted and connected to the lead. Implantation can be performed as day-case surgery. Continuous baroreflex stimulation is programmed and initiated 2-4 weeks after implantation.

\section{Clinical studies}

In the acute BaroReceptor Activation System Study (BRASS), the temporary effects of carotid baroreflex stimulation was investigated during elective carotid surgery [13]. With incremental voltage a significant dosedependent blood pressure and heart rate reduction were achieved. Maximum reductions occurred at 4-6 V. Thus, BRASS reconfirmed the assumption that device-based baroreflex stimulation was able to modulate blood pressure acutely. This proof of concept justified the evaluation of the system regarding chronic pressure reduction in hypertensive patients.

\section{Patients with resistant hypertension}

The Device Based Therapy in Hypertension (DEBuTHT) Trial was a prospective, non-randomised European multi-centre feasibility and safety study and involved 45 patients with a SBP above $160 \mathrm{mmHg}$ despite a treatment regimen comprising at least three antihypertensive drugs including one diuretic [14]. Patients remained on antihypertensive medication during the study. The primary endpoint was a decrease of SBP of at least $10 \mathrm{mmHg}$ after 3 months of device therapy; safety assessment included any serious adverse events and all procedure- and devicerelated events of any severity up to 3 years of follow-up. Mean systolic pressure before implantation was almost $180 \mathrm{mmHg}$ and mean heart rate was 80 beats $/ \mathrm{min}$. Participants were taking 5.5 antihypertensive drugs on average. After 3 months, mean pressures were reduced by more than $20 \mathrm{mmHg}$. At 2- and 3-year follow-up, this result was not only sustained, but the mean reduction was even more pronounced at over $30 \mathrm{mmHg}$ [14] (Fig. 6). Besides, the device exhibited an acceptable safety profile, and patients reported a better sleep and less headache and they could better concentrate since start of the therapy.

As a result of these findings, the US Food and Drug Administration approved a phase III trial (Rheos Pivotal 
Fig. 6 Feasibility long-term study. Decrease in systolic and diastolic blood pressure and heart rate after 1, 2, 3 and 4 years of baroreflex activation therapy. Mean systolic blood pressure was reduced from $193 / 111 \mathrm{mmHg}$ (baseline) to 140/81 (4-year results), $N=18$ [28]. bpm beats per minute

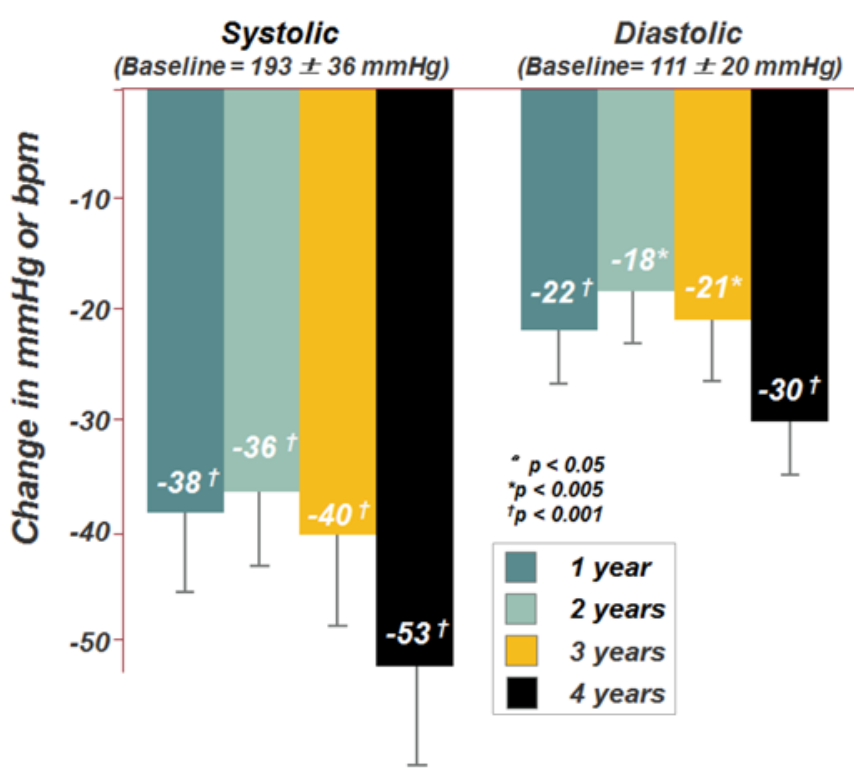

Heart Rate

(Baseline $=74 \pm 13 \mathrm{bpm}$ )

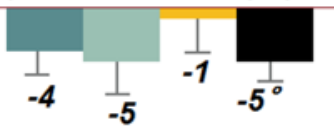

\begin{tabular}{|c|c|}
\hline $\begin{array}{r}\text { \# Anti-hypertensive } \\
\text { Medications }\end{array}$ \\
\hline Baseline & $5.0 \pm 1.3$ \\
\hline 1 year & $\begin{array}{c}-0.2 \pm 0.3 \\
(p=0.51)\end{array}$ \\
\hline 2 years & $\begin{array}{c}-0.7 \pm 0.4 \\
(p=0.14)\end{array}$ \\
\hline 3 years & $\begin{array}{c}-0.8 \pm 0.4 \\
(p=0.06)\end{array}$ \\
\hline 4 years & $\begin{array}{c}-1.6 \pm 0.5 \\
(p=0.02)\end{array}$ \\
\hline
\end{tabular}

Trial), which randomised 265 patients in the US and in Europe. It was the first large-scale randomised doubleblinded placebo-controlled trial to evaluate baroreflex activation therapy (BAT) in drug-resistant hypertension patients. One month after implantation of the Rheos system, the patients were randomised in a 2:1 fashion to either immediately turning on the device or to a 6 -month deferral with device initiation thereafter. Both patient groups were followed for 12 months after randomisation. The trial demonstrated a mean reduction in SBP of $35 \mathrm{mmHg}$ at 12 months. More than $50 \%$ of patients attained a SBP $\leq 140 \mathrm{mmHg}$, which was very promising $[15,16]$. Initially, a mild decrease of the glomerular filtration rate was observed in these patients after initiating BAT, which was considered a normal haemodynamic response to the drop in blood pressure. However, in the long-term, there was no further decrease in renal function [17].

Moreover, a substudy of DEBuT-HT involved 21 patients and analysed the correlation between blood pressure changes and changes in cardiac autonomic regulation after chronic baroreceptor stimulation [18]. In this study, chronic baroreceptor stimulation caused changes in heart rate variability, which was consistent with a sympathetic inhibition and a parasympathetic activation with correlating pressure reductions. The authors concluded that further studies were needed to investigate whether this autonomic (sympathetic) modulation might have favourable cardiovascular effects in patients with drug-resistant systemic hypertension exceeding pure blood pressure control. In support hereof, another study demonstrated that chronic Rheos' Therapy reversed left ventricular and atrial remodelling and improved arterial compliance in addition to sustained blood pressure reduction in patients with resistant hypertension [19]. These benefits were supplementary to those achieved by aggressive medical therapy and, potentially, independent of isolated blood pressure reduction. Moreover, in patients with symptomatic heart failure, chronic Rheos therapy improved functional capacity by as much as $37 \%$ when measured by a 6 -min hall walk test. Thereby, significant reductions of left ventricular mass and posterior wall thickness indicated relevant reverse left ventricular remodelling. In addition, the Rheos device was also effective in the management of uncontrollable hypertension [20].

Of note, all aforementioned studies were performed with the first-generation device using bilateral leads and electrodes. A recently published study showed that BAT delivered with the second-generation system (Barostim neo) lowers blood pressure in resistant hypertension with stable, intensive background medical therapy, consistent with studies of the first-generation system (Rheos). Besides, the safety profile was described as comparable with a pacemaker [21].

A major concern of the BAT is the potential development of decreasing responsiveness (tachyphylaxis or baroreflex resetting). But, a follow-up study of the DEBuT-HT patients demonstrated that acute voltagedependent blood pressure and heart rate decrease are preserved after at least 1 year of continuous electrical baroreflex stimulation in patients with resistant hypertension [22]. This indicates that response adaptation and nerve fatigue are unlikely to develop in long-term carotid baroreflex activation.

The described studies led to the incorporation of BAT into treatment guidelines. According to the new 2013 European Society of Hypertension (ESH)/European Society of Cardiology (ESC) guidelines, baroreceptor stimulation may be considered in patients without effect after adequate drug treatment (Class IIb, Level C) [23]. But, baroreceptor stimulation was only recommended to experienced operators and selected hypertension centres until more evidence becomes available on long-term efficacy and safety (Class I, Level C). 
A health economic analysis of baroreceptor stimulation for resistant hypertension has been performed, to assess the long-term impact on cardiovascular morbidity and mortality, as well as the cost-effectiveness of the therapy [24]. The analysis takes a societal perspective and was performed for the German setting. The analysis estimated that for a high-risk resistant hypertension patient, the lifetime impact of baroreceptor stimulation is a $35 \%$ reduction in stroke risk, $19 \%$ reduction in the risk of myocardial infarction and $23 \%$ reduction in the risk of end-stage renal disease. The average survival increase was projected to be 1.66 years, and the average increase in quality adjusted life years (QALY) was 2.17 years. The cost per QALY was estimated to be 7,797 EUR, well below the recognised cost-effectiveness threshold of 35,000 EUR per QALY [25] (Threshold values for costeffectiveness in healthcare; 2008). The study concludes that BAT may be a cost-effective treatment when compared with optimal medical management in patients with resistant hypertension.

\section{$B A T$ in heart failure patients}

As the BAT system lowers not only blood pressure but also has a beneficial effect on the heart, studies have been conducted on heart failure patients.

In a very recent study on 11 heart failure patients (New York Heart Association (NYHA) class III and ejection fraction $(\mathrm{EF})<40 \%$ ), who were all ineligible for cardiac resynchronisation, BAT was used during 6 months along with optimised medical therapy. Efficacy was assessed using serial measurements of muscle sympathetic nerve activity (MSNA); moreover, clinical parameters of quality of life and functional capacity indicators were measured. A highly significant decrease in MSNA and significant improvements in baroreflex sensitivity, EF, NYHA class, quality of life and 6-min hall walk could be achieved. Besides, hospital re-admittance rates for worsening heart failure were markedly reduced [26]. In addition, BAT seemed also compatible in patients with pre-existing implantable cardioverter-defibrillators (ICDs), and both therapies appeared complementary [27].

In addition, the Barostim Health Outcomes Prospective Evaluation for Heart Failure (Barostim HOPE4HF) in patients with left ventricular EF $\leq 35 \%$, NYHA class III trial started in April 2013 to evaluate effectiveness and safety of the Barostim neo ${ }^{\mathrm{m}}$ System in heart failure patients. This prospective, randomised and controlled study aims to enrol approximately 150 patients in multiple US and European centres to compare Barostim neo ${ }^{\mathrm{mm}}$ therapy with the current standard care for symptomatic heart failure. Study objectives are changes in EF, 6-min hall walk, NYHA classification, quality of life, creatinine, N-terminal B-type natriuretic peptide and other parameters. Results of the Barostim HOPE4HF study are awaited shortly.

\section{Current status}

At the end of August 2014, a total of 420 Rheos devices and 380 Barostim $n e o^{\mathrm{TM}}$ systems have been implanted worldwide and 8 devices in our institution. Approximately 400 devices have been implanted in study settings. All reports suggest so far that implantation can be performed with reasonable safety and that the associated risks are comparable with similar implantable devices such as pacemakers or ICDs.

In Europe, the Barostim $n e o^{\mathrm{TM}}$ device is already CE marked and commercially available in Italy, Germany, Switzerland and the Netherlands. Reimbursement is not yet regulated everywhere, but the therapy is currently in the process of being reimbursed in several European countries. An analysis has showed that the therapy is cost-effective in treating hypertension [24].

\section{Conclusion}

The BAT by the CVRx electrical carotid sinus wall stimulation system leads to sustained arterial blood pressure decrease in selected patients with resistant hypertension. The haemodynamic response is larger than anticipated and sustained at 4-year follow-up complying with the treatment goal of sympathetic modulation leading to decreased sympathetic activity. Besides, lowered arterial blood pressure and heart rate led to favourable cardiovascular effects in patients with drug-resistant systemic hypertension like reversed left ventricular, atrial remodelling and improved arterial compliance. Studies on heart failure patients are ongoing and beneficial effects have been seen in selected patients. Thus, target populations include patients with refractory hypertension and eventually heart failure who do not respond sufficiently to best medical therapy. BAT has been incorporated in the $2013 \mathrm{ESH} / \mathrm{ESC}$ guidelines. The implantation of the second-generation device is less invasive and might be more likely to convince physicians and patients for the implantation. As in pacemakers, the development of rechargeable batteries is desirable for the future. Moreover, a feedback mechanism that activates the pulse generator only when increasing blood pressure is strongly awaited.

\section{Conflict of interest}

All authors declare no conflict of interest.

\section{References}

1. Chobanian AV, Bakris GL, Black HR, et al. The Seventh Report of the Joint National Committee on Prevention, Detection, Evaluation, and Treatment of High Blood Pressure: the JNC 7 report. JAMA. 2003;289(19):2560-72.

2. Fields LE, Burt VL, Cutler JA, et al. The burden of adult hypertension in the United States 1999 to 2000: a rising tide. Hypertension. 2004;44(4):398-404. 
3. Hajjar I, Kotchen TA. Trends in prevalence, awareness, treatment, and control of hypertension in the United States, 1988-2000. JAMA. 2003;290(2):199-206.

4. Campbell DJ. Vaccination against high blood pressure. Curr Pharm Des. 2012;18(7):1005-10.

5. Wienemann H, Meincke F, Kaiser L, et al. Treating resistant hypertension with new devices. Minerva Cardioangiol. 2014;62(3):235-41.

6. Brest AN, Wiener L, Bachrach B. Bilateral carotid sinus nerve stimulation in the treatment of hypertension. Am J Cardiol. 1972;29(6):821-5.

7. Koch E. Die reflektorische Selbststeuerung des Kreislaufs. In B. Kisch, Editor. Dresden-Leipzig: Th. Steinkopff 1931.

8. Muratori G. Histological observations on the structure of the carotid sinus in man and mammals. In: Kezdi P, editor. Baroreceptors and hypertension. Oxford: Pergamon; 1967. 253-65 p.

9. Peters TK, Koralewski HE, Zerbst E. Blood pressure and heart rate changes during physical activity upon heart rate feedback-controlled electrical carotid sinus nerve stimulation. Int J Cardiol. 1989;22(3):389-92.

10. Lohmeier TE, Irwin ED, Rossing MA, et al. Prolonged activation of the baroreflex produces sustained hypotension. Hypertension. 2004;43(2):306-11.

11. Scheffers I, Schmidli J, Kroon A, et al. Sustained blood pressure reduction by baroreflex hypertension therapy with a chronically implanted system: 3-year data from the Rheos DEBuT study in patients with resistant hypertension. J Hypertens. 2009;27:S421.

12. Tordoir JH, Scheffers I, Schmidli J, et al. An implantable carotid sinus baroreflex activating system: surgical technique and short-term outcome from a multi-center feasibility trial for the treatment of resistant hypertension. Eur J Vasc Endovasc Surg. 2007;33(4):414-21.

13. Schmidli J, Savolainen H, Eckstein F, et al. Acute devicebased blood pressure reduction: electrical activation of the carotid baroreflex in patients undergoing elective carotid surgery. Vascular. 2007;15(2):63-9.

14. Scheffers IJ, Kroon AA, Schmidli J, et al. Novel baroreflex activation therapy in resistant hypertension: results of a European multi-center feasibility study. J Am Coll Cardiol. 2010;56(15):1254-8.

15. Bisognano JD, Bakris G, Nadim MK, et al. Baroreflex activation therapy lowers blood pressure in patients with resistant hypertension: results from the double-blind, randomized, placebo-controlled rheos pivotal trial. J Am Coll Cardiol. 2011;58(7):765-73.

16. Bakris GL, Nadim MK, Haller $H$, et al. Baroreflex activation therapy provides durable benefit in patients with resistant hypertension: results of long-term follow-up in the Rheos Pivotal Trial. J Am Soc Hypertens. 2012;6(2):152-8.
17. Alnima T, de Leeuw PW, Tan FE, et al. Renal responses to long-term carotid baroreflex activation therapy in patients with drug-resistant hypertension. Hypertension. 2013;61(6):1334-9.

18. Wustmann K, Kucera JP, Scheffers I, et al. Effects of chronic baroreceptor stimulation on the autonomic cardiovascular regulation in patients with drug-resistant arterial hypertension. Hypertension. 2009;54(3):530-6.

19. Bisognano JD, Kaufman CL, Bach DS, et al. Improved cardiac structure and function with chronic treatment using an implantable device in resistant hypertension: results from European and United States trials of the Rheos system. J Am Coll Cardiol. 2011;57(17):1787-8.

20. Mohaupt MG, Schmidli J, Luft FC. Management of uncontrollable hypertension with a carotid sinus stimulation device. Hypertension. 2007;50(5):825-8.

21. Hoppe UC, Brandt MC, Wachter R, et al. Minimally invasive system for baroreflex activation therapy chronically lowers blood pressure with pacemaker-like safety profile: results from the Barostim neo trial. J Am Soc Hypertens. 2012;6(4):270-6.

22. Alnima T, Scheffers I, De Leeuw PW, et al. Sustained acute voltage-dependent blood pressure decrease with prolonged carotid baroreflex activation in therapy-resistant hypertension. J Hypertens. 2012;30(8):1665-70.

23. Task Force for the management of arterial hypertension of the European Society of H, Task Force for the management of arterial hypertension of the European Society of C. 2013 ESH/ESC Guidelines for the management of arterial hypertension. Blood Press. 2013;22(4):193-278.

24. Borisenko O, Beige J, Lovett EG, et al. Cost-effectiveness of Barostim therapy for the treatment of resistant hypertension in European settings. J Hypertens. 2014;32(3):681-92.

25. Eichler HG, Kong SX, Gerth WC, et al. Use of cost-effectiveness analysis in health-care resource allocation decisionmaking: how are cost-effectiveness thresholds expected to emerge? Value Health. 2004;7(5):518-28.

26. Gronda E, Seravalle G, Brambilla G, et al. Chronic baroreflex activation effects on sympathetic nerve traffic, baroreflex function, and cardiac haemodynamics in heart failure: a proof-of-concept study. Eur J Heart Fail. 2014;16(9):977-83.

27. Madershahian N, Scherner M, Muller-Ehmsen J, et al. Baroreflex activation therapy in patients with pre-existing implantable cardioverter-defibrillator: compatible, complementary therapies. Europace. 2014;16(6):861-5.

28. Kroon AA, Schmidli J, Scheffers I, et al. Chronically implanted system: 4-year data of Rheos DEBuT-HT study in patients with resistant hypertension. J Hypertens. 2010;28(e-suppl. A):278. 